\author{
James Kendall \\ University of Salento \\ e-mail: kendalljames2@gmail.com \\ ORCID: 0000-0003-4698-1791
}

\title{
PLANTING THE SEEDS OF ARTISTIC SUBVERSIVENESS IN À BOUT DE SOUFFLE: GODARD'S TRAILBLAZING CINEMATIC LANGUAGE
}

\begin{abstract}
The following article frames a particular case study: Jean-Luc Godard's $\grave{A}$ bout de souffle (1960), referenced in the paper with its American title, Breathless. Foraging through the dense and sophisticated thicket of narrative, visual and textual features, the present study will attempt to untangle the overall intrinsic complexity of Godard's film, as it exceeds simple commonalities between genre conventions or traditional stylistic approaches.

The abrasive dialectical opposition that Breathless enacts against classical storytelling is indeed central to the specific cluster that can be examined under the labels of "experimental cinema", "auteur cinema", "art cinema", predicated on Godard's abundant departures from cinematic (mainstream) norms.

The methodology adopted in the article will encompass both a cultural studies approach and the visual strategies of textual analysis from the perspective of film studies. This will spur a close examination of Godard's directorial style, paying attention to a rich plethora of technical devices inscribed within salient sequences and offset against the matrix of creative options presented by the French Nouvelle Vague.

Keywords: narration, characterization, textual analysis, language and transcreation, editing, visual discontinuities, jump-cuts, auteur cinema, nouvelle vague.
\end{abstract}

Criticism has taught us to love both Rouch and Eisesenstein and that we must not neglect one sort of cinema in the name of some other mode. A young writer today is aware of Molière and Shakespeare. Well we are the first directors to be aware of D.W. Griffith. Even Marcel Carné, Louise Delluc and René Clair had no real critical or historical background.

Godard, "Interview withGodard", Godard on Godard, 178

\section{Introduction: Background to the film and its revolutionary status}

Jean Luc Godard's Breathless can be considered, in many ways, not only as a highly significant and remarkable New Wave film but also as a crucial landmark in film history. Its revolutionary style and overall amazing stance 
towards the language of cinema make Breathless both a defining watershed within the context of the French New Wave and the zenith of experimental filmmaking.

Every account of Godard's film as a canonical New Wave picture must bear in mind not only the fact that Godard's entire oeuvre has intended to set the standards for a new aesthetic, but primarily that the film has tried to explore an unknown continent in the aesthetics of cinema in general. By smashing the boundaries of the conventionally filmable, Breathless is both representative of the New Wave aesthetics but also unique in this context.

The point of this essay is engaged with the dual nature of the film, which is as both a vehicle of the New Wave's spontaneity and as the most revolutionary work within this context. In this respect, I shall focus on both the narrative structure and the overall style of the film, highlighting the great unconventionality and freshness of Godard's mise-en-scène and cinematic language.

As in the case of all Godard's films, Breathless is an extremely complex work. The film in fact, as David Bordwell argues, strongly jettisons narrative comprehension (1985) This is not simply a problem of interpretation succumbing to the intricacies of a thematically ambiguous work. Godard'sfilms potentially allow for high-level "readings". The real "problem" is that Breathless remains problematic on a simple denotative level. The visual and aesthetic dynamics of the film in fact strongly de-familiarize the average spectator, defying analysis. Fotiade aptly dwells upon such intrinsic complexity when he states that across the critical literature on Breathless there is apparent consensus that the film is postmodern, existential and metatextual and that almost every film critic sees it as the archetypal text par excellence in film studies which eschews traditional narrative construction or conventional cinematic grammar (2013).

Thus, to grasp how the film works (both diegetically and extradiegetically) one should focus on Godard's aesthetic agenda and directorial sensibility, in order then, to see how the film showcases its trailblazing cinematic language.

\section{Godard's aesthetic rationale}

Godard like Truffaut or Chabrol was a potent, sometimes abrasive critic. Like most New Wave directors, his background as a film critic was to be highly significant for his career as a filmmaker. 


\section{Planting the Seeds of Artistic Subversiveness in "À Bout de Souffle"...}

If, as Richard Neupert claims, Truffaut has become over the years the ideal figure to personify the term New Wave, Godard still fits this description but also manages to transcend it, taking the New Wave's avant-garde style to the extreme (2002). This is clearly visible in Godard's peculiar conception of cinema. Unlike Truffaut, for example, who interweaved cinema history with his own personal history, Godard saw film history as something more complex than simple mise-en-scène options. Each cinematic device was for Godard the gateway to endless narrative and cultural possibilities. In this way the New Wave tenet which saw the cinema as a personal means of expression, has been powerfully surpassed.

For Godard cinema becomes the principal instrument of culture formation and of the representation of reality. Such a conception of cinema is perfectly envisaged by Godard's analysis of a particular scene in The Wrong Man:

The beauty of each of these close-ups, with their searching attention to the passage of time, comes from the sense that necessity is intruding on triviality, essence on existence. The beauty of Henry Fonda's face during this extraordinary second which becomes interminable is comparable to that of the young Alcibiades described by Plato in The Banquet. Its only criterion is the exact truth. We are watching the most fantastic of adventures because we are watching the most perfect, the most exemplary, of documentaries.

Godard, "Interview with Godard", Godard on Godard, 8

As evident in the extract of Godard's critical review, the gist of the scene is revealed through a single shot in The Wrong Man, which he explains, is equivalent to the documentary form or the non-fiction aesthetic language. The documentary-like nature of the scene allows for a reconceptualization of the narrative outside the purely diegetic realm of the film. The moment for Godard seems to be imbued with real life experiences and hence, reveals his preference towards a representation of reality. The focus on particular images engendersa profound interest for imagery aesthetics, where impressions are channelled through the poetics of the image, rather than the film's overall meaning. The appreciation of colours, expressions, gestures, and textures give value to partial detail, rather than to the intentional construct. These details, found especially poignant, reject the predictable nature of a constructed cinema, and emphasise the art of the accidental. A reading of cinema that neglects the conception of the narrative in classical terms and favours an aestheticized interpretation and rendition of the story, further advances the critique of Hollywood by subverting the dominant, classical and orthodox reading relative to the construction of the narrative. 
It is now clear that this revolutionary attitude to the cinematic medium, was to become the real engine driving Breathless. Michel Marie's study of the film's production is here significant not only because it provides hints of the New Wave aesthetics but mainly because it prepares for the great revolutionary spirit of the film. Godard, like other New Wave directors, rejected artificial lighting and studio's machinery in favour of hand-held cameras, improvisation and plan-of-action scripts.

But from the very beginning, Breathless was conceived as something completely different from what cinema had previously done. With its primitive and apparently "unprofessional" aura, Godard's picture had to give the feeling that the techniques of filmmaking "had just been discovered for the first time" (2000). Thus, the modus operandi of Breathless's production appeared to be more unconventional and "personal" than even most of its contemporary New Wave films.

\section{A close examination of Breathless: structure and style}

Having highlighted the film's background and author's filmmaking rationale, I shall now move to the text itself, focusing on narrative structure and style.

According to James Monaco, Breathless was acknowledged as something utterly revolutionary right from the start (1976). Truffaut's The 400 Blows was innovative in its own right, but it existed within a well-established cultural and cinematic realm (namely the New Wave). Breathless instead could not be contained or restricted within a precise artistic framework. It is exactly in this context of irreducibleness that one finds the very heart of the film's uniqueness.

The following analysis will delve through the complex gamut of narrative and formal features. Godard's story construction is more fragmented than that of many of his contemporaries. The overall story structure is chronological, yet Godard presents incomplete shards of action and often reduces the most significant narrative events to brief and confusing scenes. The central characters of the film, Michel and Patricia, are powerfully ambiguous. As the story evolves, the audience gradually learns about the characters' concerns and goals, but there is never an attempt from Godard to explain character motivations or clarify Michel's and Patricia's relationship. As in the art film, the two protagonists are presented from the beginning in media res. Patricia especially, as Neupert stresses, is a typical 
Planting the Seeds of Artistic Subversiveness in "À Bout de Souffle"...

art film character, highly fascinating (a sort of femme fatale) but also incomplete (2002).

Michel and Patricia are characters without a genre, always out of place, and their existential drifting maps out a visual vocabulary which fully endorses the terrain of anxiety and emotional displacement in which the two protagonists operate.

An elucidation of Patrizia's character is thus poignant as it sheds light on the interconnectedness between characterization and narrative and the symbiotic relationship between the two. Patricia Franchini's character is intertextual through the elements that hark back to her past roles in Otto Preminger's Saint Joan (1957) and Bonjour Tristesse (1958)1. Seberg's miscasting in the controversial film Saint Joan and poor performance in Bonjour Tristesse, would become the platform from which Godard formulated Patricia's identity crisis. Her boyish haircut for instance, is a consequence of her heavily criticised role in Preminger's film, Saint Joan, which paired with her identity crisis in Breathless, further enhances the subversion of established representations of femininity in Hollywood's American noir. Her androgyny adds to her feminine power - her ambition, style and charm as Godard explores the struggle for women in the changing conditions of feminism in modern French society. Her existential confusion too, especially clear when she confesses to her friend, Van Doude, "I don't know if I'm unhappy because I'm not free, or if I'm not free because I'm unhappy", also identifies with her failed stardom, and Breathless as Seberg's search for an alternative to the Hollywood system. Patricia's interview with novelist Parvulesco (French director, Jean-Pierre Melville), is also an interrogation of Patricia's crisis, with the scene's objective to explore the comparative differences between French and American women. According to Fotiade, the character of Patricia presents the challenges of an American female in the Parisian existential climate, with her commitment to the inherent values of society colliding against her hunger for independence (2013).

Beyond its story, Breathless is at its most revolutionary in its narrative style. While the jump-cut is the most famous and obvious device that rendered Godard's work unique within the New Wave context, a matrix of other strategies function to deliver the revolutionary nature of the film.

The great stylistic complexity of Breathless can be subdivided into three main categories: the jump-cut with its spatial and temporal discontinuities, the long takes and the dialogue.

Right from the beginning of the film, Godard's mise-en-scène violates those codes of spatial and graphic continuity editing that had been so scrupulously observed up to 1959. The first sequence of the film where 
Michel is shown stealing an American's officer's car with the help of an unknown woman is exemplary in its attempt to establish themain patterns of the film's style and flaunt the abrasive cinematic grammar deployed by the director: the hand-held camera lends a documentary-quality texture to the shots, continuity editing is powerfully rejected, the eye-line matches aredisrupted and finally, but not less importantly, the soundtrack is emphasized as an artificial construction, often disconnected from the images throughout the film. Hence, both the visual landscape and the soundscape disrupt character presentation and overall exposition.

The second sequence which unfolds on the road between Marseilles and Paris (as Michel is pursued by the police) strongly jettisons the conventions of continuity editing, featuring one of the most radical devices of the film: the jump-cut. According to Valerie Orpen in her analysis of this bewildering sequence, the moment in the film is extreme. Although classical action sequences challenge common conventions for dramatic purpose, the sequence under consideration is viscerally disruptive (2000). Notonly is the $180^{\circ}$ line crossed, but there are also constant leaps between shot-scales which disorientate the spectator. Such de-familiarizing effecton the audience has, for Godard, the function of activating the spectator. Although ambiguous, we respond to the sequence (and to the film as a whole) as if it wereauthentic. In this way, the discontinuity of the style becomes Godard's filmic rhetoric. The film's strong unpredictability becomes the vehicle through which Godard constructs an active spectator, one who is being constantly challenged. Godard's notes on editing are here particularly relevant:

Knowing just how long one can make a scene last is already montage. Certainly a brilliantly directed film gives the impression of having been placed end to end, but a film brilliantly edited gives the impression of having suppressed all direction... Invention and improvisation takes place in front of the movieola just as much as it does on the set. Cutting a camera movement in four may prove more effective than keeping it as one shot.

Godard, "Interview with Godard", Godard on Godard, 40

\section{Discontinuity editing: a language of subversiveness}

The polarized tension between invention and improvisationcan be fully appreciated in the sequences containing a quick succession of jump-cuts. Like Godard's entire arsenal of narrative tactics, the jump-cut is highly significant since it calls attention to the ingrained artificiality of the medium and to Godard's authorial presence. 
According to Valerie Orpen, the most outrageous aspect of the jumpcuts in Breathless is their gratuitous nature (2000). What is thus revolutionary is not their endorsement, but the lack of motivation behind them. In light of Orpen's analysis, the jump-cuts have no function in the film if not that of creating a deliberate intrusive effect thereby attesting the director's constant presence.

It is exactly in this context of powerful encroachment that one fully realizes the significance of the jump-cuts. As Orpen claims, Godard knew exactly what he was doing with the use of jump-cuts: the editing had to be disjunctive, in order to mimic Michel's "breathless" nature (2000). Although Godard employed an editor, the jump-cuts are definitely his idea and come as Godard's most personal signature. In this way they cement Godard's position as an auteur in the New Wave sense of the term, that is as a director who is involved in every stage of the filmmaking process. ${ }^{2}$ In addition, the jump-cuts have the function of shaping the characters' portrayal, thus mirroring the New Wave concept of style as a vehicle to convey characterization.

If one takes three main sequences in the film (the car chase on the Route Nationale 7, Patricia's and Michel's driving through Paris and Patricia's meeting with the journalist Van Doude in a Champs-Élysées cafè) it is possible to see how such a storytelling device functions in relation to characters, shedding light on the interconnectedness between characterization and the highly stylized quality of the mise-en-scène.

After the stasis of the opening sequence, the Route Nationale's scene conveys an impression of speed which mirrors Michel's impatience and kinetic energy. In order to unleash Michel's breathless nature and to shorten the long journey, Godard employs jump-cuts (both spatial and temporal) which make the film jerk forward. The cuts have thus the effect to move the narrative forward, reducing the distance between Michel and his goals (get to Paris, get the money he needs off a friend and ultimately find Patricia).

The second sequence employs the jump-cut effect to shape Patricia's character. What we get, as Neupert argues, is a character in bits and pieces (2002). Instead of deploying a traditional shot/reverse shot camera set-up, Godard fragmentizes Patricia's body as she tries to explain her feelings for Michel. Although we do not actually see the physical process of fragmentation, the effect is strongly overt: as Michel mocks her, citing the woman's body parts, Godard perfectly juxtaposes, in a beautiful rhythmic way, Michel's words with the jump-cuts. Despite the fact that the continuity of the soundtrack softens the cuts and the rhythm achieves a musicality ofits own, the result is perturbing. It also mirrors the audience's inability 
to fully comprehend Patricia's character, eternally shattered in the spectator's mind.

The third sequence under consideration achieves a more provocative status as it literally "butchers" Van Doude's character, the journalist interviewed by Patricia. The shots that accompany Patricia to the meeting in the cafe are staged according to the classical continuity editing patterns with a battery of traditional shots: two shots and shot/reverse shots. But when Van Doude tries to cheer Patricia up (preoccupied by her possible pregnancy) Godard introduces the jump-cuts which disrupt Van Doude's story. The effect is a rather comic portrayal of Van Doude's persona. The journalist in fact has no dramatic spine until the jump-cuts begin. Afterwards, he becomes a clownish and conceited figure, perfectly mirrored by the sense of restlessness caused by the jump-cuts. One might even argue that such jump-cuts indicate Godard's impatience and lack of respect for Van Doude's figure, a further indication of the intersection of visual language and character design.

Overall, the use of jump-cuts in Breathless is a testimony of Godard's dominant position in the film. Aesthetically, the jump cuts portend the possibility to fast-forward, except in Godard's film it is the director who controls this function, not the viewer, a further proof of the New Wave conception of the filmmaker as real auteur.

What makes the jump-cuts in the film so revolutionary is their radicalmotivation. Whereas the jump-cuts were already present in early cinema (as acinematic attraction) but also in the New Wave itself - think of Truffaut's use of thesame device in Jules and Jim - the jump-cuts in Breathless are yes intentional, but their purpose is unclear. Not only are they visually ambiguous, but conceptually they do tend to push the boundaries of traditional storytelling.

\section{The use of long takes}

Strictly connected with the use of jump-cuts is the employment of long takes. According to Valerie Orpen there are nine long takes in Breathless (2000, 79). Most of them are by no means static, possessing a rhythm of their own. Both the long takes and jump-cuts (traditionally hailed as antithetical) have in Godard's film a similar function: to unleash a feeling of heightened kinesis and perpetual movement.

If one takes the sequence where Patricia, after having reported Michel to inspector Vital, returns to their hideout and finds Michel sitting, listening 
to Mozart, it ispossible to fully appreciate Godard's use of the long-take. As for the rest of the film, the long take has the function of shaping characterization. As Patricia explains to Michel the reasons behind her choice to go to the police, the camera constantly tracks her movements. Both the lighting and Patricia's slow pace and body language invite the audience to fully focus on her screen persona. Patricia is once again depicted as an ambiguous character: as she slowly walks around, a sense of randomness is inscribed in the sequence, the same sense of casualty that had characterized Patricia's persona from the very beginning of the film (the walking up and down Les Champs-Élysées is another poignant example). In addition, the background diegetic music, constantly audible even when Patricia moves away, conveys both a sense of tragedy (preparing for the following events) but also reinforces Patricia's screen persona. The extensive duration of the shots and the low camera angles powerfully frame Patricia's character, as if she is on stage. When Michel turns the radio off, the emotional interaction between the two characters is emphasized. The long take continues to follow Patricia's random movements while the absence of music aurally mirrors the weight and importance of the dialogue (this is in fact the very moment when Patricia explains, although uncertainly, her own motivations). When Patricia sits down to rest, the camera (without cutting and thus breaking the flow of emotions that characterize the sequence) passes to cover Michel's movements. When Michel starts to speak, the camera sticks with his movements, embracing him in a backward track. In contrast to the long takes on Les Champs-Élysées, there is nothing here which distracts the viewer, such as background movements for example. Godard relies on the extensive duration of the shots and low camera angles tovisually represent Michel's emotional upheaval. The same sense of casualty (as Michel randomly walks around) accompanies the character's movements, reinforcing the similarities between the two protagonists. There is in fact something poignant in Patricia's physical movements as opposed to the stasis and sedentariness of her lifestyle or plans for the future. If Patricia had previously been a "static" character (often seen waiting), from this moment onwards she is in constant movement, mimicking the enhanced kinetic energy embraced by the miseen-scène. Both Michel and Patricia lack a precise goal or aim, without a specific spatial orientation; they endlessly "float" through the streets of Paris or inside their apartments. Thus, the function of the long take here is to unite the characters in the name of their "breathless" nature. The last shot of the sequence, a panning movement from Patricia's face to Michel, violently disrupts the previous equation between the two protagonists. Michel's final line "I just want to rest" jettisons his previous relationship with Patricia. 
This reversal culminates in the moment in which Godard's camera visually displays Michel's stasis and Patricia's disquiet, as if Michel had transferred his energy to the woman.

In this way Godard aptly fuses together his stylistic flamboyance with character design. If the quick cuts, long takes and general "cinematic hyperactivity" give an impression of avant-garde technique and overall speed, they ultimately function as the best way to define Michel's restless "automative" character.

Yet the style of Breathless, as Orpen stresses, works perfectly as a New Wavesignifier, providing a manifesto for Godard's idea of a new cinema which rejects the continuity rules of the "Tradition of Quality" (2000). In light of this final statement, Breathless is both a filmic and political affirmation of its auteur's rhetoric, and thus a perfect example of a New Wave text.

\section{Dialogue and cinephilia: lexical foundations in the realm of film studies}

The postmodern, metatextual and existential qualities of the film are further predicated in the use of dialogue scenes. According to Michel Marie, the most fundamental innovation of Breathless is the cinematic dialogue which comprises the most revolutionary use of language since the coming of sound (2000). Visual discontinuity is perfectly mirrored by the overall autonomy of the soundtrack, which comes as independent from the image. Neupert argues that Michel Poiccard was the first film character to violate the refined sound conventions of 1959 French cinema by using popular slang and the most trivial spoken French (2002). In this respect Michel's character produces a totally new linguistic texture, refracted through a wealth of popular and slang terms and expressions.

The use of language in the film has two interrelated functions: on the one hand, it helps to delineate character differences, while on the other, it provides the audience with an endless succession of intertextual references to other movies, and also to art, painting, music and literature.

The great wealth of the verbal material used by Michel and Patricia not only structure an opposition between the two protagonists, but also between two different but interwoven cultures. Homi K. Bhabha's approach to the postcolonial finds fertile ground in the light of the previous statement: the linguistic and cultural negotiation that the film enacts is positioned on the liminality and interstices between different worlds ${ }^{3}$. If the variety of 
different languages (American, French, Italian, Spanish), makes Breathless a tragedy of language and of the impossibility of communication, the numerous movie references establish a backdrop for Michel's and Patricia's characters (a sort of mise-en-abyme in the film) and simultaneously acknowledge Godard's authorial presence and cinephilia. Michel's behaviour is presented throughout the film as mirrored by the movies Breathless references. The constant imitation of Bogart by the protagonist becomes the triumphant artefact of a culture of which Michel is the copy, the dupe.

As Michel's story unfolds throughout the narrative, one strongly acknowledges how much Godard's intertexts are deliberate and carefully chosen. They all point out Godard's strong admiration for the very essence of the American cinema. According to Jefferson Kline, Godard's American cinephilia is an admiration for the soul, the secrets of characterization, the belief in characters' portrayal, revealed rather than informed by action (1992). Dudley Andrew has skilfully unearthed the hodgepodge of dense cinematic allusions, to reveal the "Hollywood love story" implicit in the whole film. The theme of Breathless, Andrew states, like the essence of its hero, is precisely the futile (and fatal) struggle to be original in the "manner of someone/something else" (1995). The notion of individuality is as American as the movies which Breathless directly addresses. Thus, the choice of constantly quoting film noir comes as no real surprise, since it represents the genre that most promoted and problematized the theme of individuality. ${ }^{4}$ It is exactly the choice of the genre that determines how the film will end. In light of this statement, Michel's betrayal acquires a new status. It is he who must pay with his own life for Godard's fidelity to the noir/detective genre. Hence, the ending functions as Godard's ultimate attempt to pay homage to his own cinephilia.

Fotiade's claim that Breathless translates "Hollywood codes into New Wave jargon" is in this respect particularly adroit (2013). Undoubtedly, the mere fact of changing words even by paraphrase changes the essence of a text, and translating can radically affect the nature of the entire work at every semiotic level, not just linguistic. ${ }^{5}$ In constructing the French backdrop, Godard has scattered a series of explicit references to American culture. For example, in one scene Patricia sells the New York Herald Tribune on the monumental Champs-Élysées. Michel on the other hand dissolves into the Parisian backdrop and is often used as an instrument in constructing the viewer's idea of a particular place. Unlike Patricia's selling of newspapers, her journalist assignments, scheduled meetings at cafés with her work associate, Michel lacks any sense of attachment to an environment and is often seen pointlessly 'hanging out' by himself on the streets of Paris. 
A chain of references to several films including the works of filmmakers, Mark Robson, Budd Boetticher, Bretaigre Windust, Otto Preminger and Robert Aldrich, is included between Godard's use of the 'outdoor/public studio', often using Michel's aimless wondering as the vehicle for a series of citations. Michel walks past the Aldrich film poster on a Parisian street of 10 Seconds to Hell (1959) with the slogan "Vivre dangereusement jusqu'au bout" (to live dangerously till the end) cited specifically because at that time Aldrich was part of the French New Wave directors' cinéphile references. The action in The Enforcer (1951) (staring Bogart) is cited when Michel attacks a man washing his hands in a public toilet and robs him of his money. The film posters of Budd Boetticher's Westbound (1959) and the film itself are referenced as Michel and Patricia see the film at the theatre and kiss longingly throughout. Another separate reference made in the movie theatre is the soundtrack of Otto Preminger's Whirlpool (1949). And lastly, a direct reference to Robson's The Harder They Fall (1956) when Michel encounters an actor's profile of Humphrey Bogart advertising his last film, clearly articulates the film as an example of cinephilia.

Such a process of domestication or ethnocentricity which operates as a form of translation for the American market is attested to by Stephen Sartinelli who has translated Andrea Camilleri's culturally and linguistically specific Sicilian novels, which often make use of the Sicilian dialect together with standard Italian: "Ma c'è pure il fatto che l'America accetti l'altro solo purchè esso diventi Americano, innanzitutto linguisticamente" [our emphasis]. ${ }^{6}$ This powerful spectrum of intertextual references also affects the portrayal of Paris. Most New Wave films are, in the literal sense of the term, real "love letters to Paris", where the city becomes a fictionalized secondary character, continuously witnessing, as a silent chorus, the characters' stories. The Paris of Breathless is a modern mishmash and allegorical setting that is totally different from the city of The Cousins or The 400 Blows. But as in those films Paris is continually signifying, stressing how the New Wave mise-en-scène aptly fictionalizes the locations selected and the different worlds explored. One could further argue, in this respect, that Godard advocates for a process of transcreation ${ }^{7}$.

Overall, if one wants to pay justice to the intrinsic complexity of Godard's Breathless, it is necessary to acknowledge the dual nature within it. Breathless at once has broken new ground within film history, but it also strongly acknowledges its debt to the New Wave movement. Further proof of this comes with the fact that Michel and Patricia have become the ultimate New Wave couple, exemplary items of the most fascinating of all film movements. 


\section{Conclusions}

Undoubtedly Godard's Breathless is unique as it attempts to create a successful and engaging narrative at the intersecting point of diverse and unconventional aesthetic strategies. The conundrum of auteur cinema vs. mainstream cinema that has always troubled film critics, is suitably epitomized by Godard's efforts to interweave Hollywood cinematic conventions with a quintessentially French existential context. Considered in many ways as a trailblazer, having epitomized and sparked the Nouvelle Vague movement, the film eschews categorization. In essence, it is a film that, like its characters' existential drifting, thrives on the immense spectrum of visual and narrative eccentricities it endorses. Breathless is thus a pop artefact and a daring work of art, made at a time when the two possibilities existed in a state of ideal confluence. That is the source of its uniqueness. Despite its influence on the immense plethora of subsequent films and diverse genres, there is still nothing else quite like it. As Tom Stoppard's character, Septimus, in Arcadia, reminds us, nothing is new, everything has already been invented: "We shed as we pick up, like travellers who must carry everything in their arms, and what we let fall will be picked up by those behind". Breathless ideally epitomizes such process of "shedding" its revolutionary skin for the future of movies to capitalize on. ${ }^{8}$

\section{N O T E S}

${ }^{1}$ Her last name is Franchini, which has Italian resonances (although "franc" could be a reference to France, too), but seems rather ironic in that it suggests she is frank, honest ("franchi" is the plural form of the Italian adjective). "Franchi" as a past participle also means "crossed over" in French, which possibly makes reference to her crossing various ethical lines.

2 Of course, other directors may have similar claims over auteurship, but Godard is clearly a more radical embodiment of this quasi God-director than his contemporaries. He is famously controlling on set, to the point of feeding lines to the actors as the camera rolls.

3 Bhabha, H, 2004, The Location of Culture, Routledge, London.

4 Although almost every film critic acknowledges Breathless's indebtedness to film noir as the genre to reference par excellence, Godard's film departs from certain tropes of the visual battery of film noir. The film in fact is not reliant on hyper-stylized angles and lighting, eschewing extensive use of low or Dutch angles as well as low and high-key lighting in the tradition of chiaroscuro cinematography.

5 As Benedetto Croce points out (1908: 23): "Ogni espressione è espressione unica".

6 Sartorelli, Stephen, 2004 "L' attivita' linguistica di Camilleri in inglese", ll Caso Camilleri, Sellero, Palenno. 
7 This term is borrowed from marketing and refers to the localized rewriting of texts with the intended (but perhaps optimistic) goal of creating the same impact as the original language message in the target audience, see Iaia 2016.

8 Stoppard, T., 1993, Arcadia, Faber and Faber, London.

\section{R E F E R E N C E S}

Andrew, D. (1995). Breathless. New Brunswick, N.J: Rutgers University Press.

Bhabha, H. (2004), The Location of Culture. London: Routledge.

Bordwell, D.(1985). Narration and the Fiction Film. Madison: University of Winsconsin Press.

Croce, B. (1908). Estetica come scienza dell'espressione e linguistica generale. Bari (Italy): Giuseppe Laterza e Figli.

Fotiade, R. (2013). À Bout de Souffle: French film guide. London: I.B. Tauris.

Godard, J. L. (1986). Montage my fine care (T. Milne, Trans.). In T. Milne \& J. Narboni (Eds.), Godard on Godard. London: De Capo Press.

Godard, J. L. (1972). Godard on Godard: Critical Writings. Edited by Jean Narboni and Tom Milne. New York: Viking.

Iaia, P. L. (2016). Analysing English as a Lingua Franca in Video Games. Linguistic Features, Experiential and Functional Dimenasions of Online and Scripted Interactions. Bern. Peter Lang.

Kline, T. J. (1992). Screening the Text: Intertextuality in the New Wave French Cinema. Baltimore: Johns Hopkins University Press.

Marie, M. (2000). It Really Makes You Sick. In Hayward S. and Vincendeau G. (Eds.) French Film: Texts and Contexts. London: Routledge, 201-215.

Monaco, J. (1976). The New Wave: Truffaut, Godard, Chabrol, Rhomer, Rivette. New York: Oxford University Press.

Neupert, R. (2002). A History of the French New Wave Cinema. Madison: University of Wisconsin Press.

Orpen, V. (2000). Film Editing. London: Wallflower Press.

Sartorelli, S. (2004). ll Caso Camilleri. Palermo: SelleroEditore.

Stoppard, T. (1993). Arcadia. London: Faber and Faber. 